\title{
Computer - Aided RGB analyses of images
}

\author{
Alion Alizoti \\ Department of Physics, Faculty of Natural Sciences, University of Tirana, \\ Bvd. Zogu I, Tirana, Albania \\ E-mail: alion.alizoti@fshn.edu.al; $\quad$ alion.alizoti@yahoo.com
}

\begin{abstract}
Computers have long been applied to physics and education. Considering that computer technologies are affecting science in many ways, special attention is payed to images and image analyses. RGB processing is used to analyse several computer images and presented with this papper. Furthermore, numerical data from images are used to tables and graphs, to motivate students devoted to science and research.
\end{abstract}

Keywords: computer, image, color, analysis, process

\section{Introduction.}

Computers are first introduced to the world some hundred years ago. Computers and computer technologies are successfully applied everywhere, and mostly science, scientific research or science education [1. SEP, 2017]. There are many features of computer technologies science is taking grace of:

1. Text typing and text display: Although some people keep using traditional typing machines, computers are continuosly replacing this old fashion activity. Keyboard, mouse, screen and computer memory are of great help for writings and printing [2. History of Computers and Computing, 2016].

2. Image taking and image display: Images are an outstanding graphic feature of computer technologies. Taking, displaying and working with images is a dynamic part of the modern era of informatics [3. CF101: A Computer Graphics Industry Reference].

3. Data and calculations: Working with numbers is probably the strongest feature of computers helping people with either basic math or elevated calculus, i.e. Pascal triangles [4. Carević et al., 2020][5. Carević et al., 2020]. 
4. Data Tables and Graphs: Data of any kind are also written in tables of different shapes and colors. They are also drawn into graphs having that sudden impact that mathematical relationships are ment to [6. Foley et al. 1990].

5. Movies, videos, animations, music, etc. Playing movies, videos or soundtracks is the fascinating feature of computers to entertainings, education, scientific or other purposes. Animations of two, three or more dimensions are also created and used to visualizations or simulations [7. Beck, 2005].

6. Visualizations and Simulations: Visualizations and Simulations are two key elements of computer activities, useful to, physics [8. White, Alizoti, 1995][9. Alizoti, White, 1997], education [10. Alizoti, Çorati, 1995], or engineerings [11. Fratila et al, 2020]. Throught out years, programms concerning visualizations and simulations of phenomena have growingly developed in physics and other sciences as well [12. Phet].

7. Experiments on - line (al): On - line experiments are the next step of computer evolution in education and science. Sensors and interfaces are produced to replace traditional measuring equipments and provide accurate data. Therefore, precision measurements serve to perfecting methodologies and, hence, to avancing accurate theoretical knowledge [13. Alizoti et al., 2013]. Available sensors and interfaces in physics can be used to study phenomena from mechanics [14. Alizoti et al., 2020][15. Alizoti et al., 2021], thermodynamics [16. Alizoti et al., 2015], hydromechanics [17. Alizoti, Dhoqina, 2021] or other fields [18. Logger Pro]. Available sensors and interfaces are provided for other natural sciences too [18. Logger Pro].

8. Communications and internet - Computers, personal clients or servers, have surrounded Earth by a network of digital communications and informations [19. World Internet Users Statistics, 2017].

9. Programming - All these features of computer technologies are based on specific programs, which need proper knowledge and skills to develop [20. Bebbington, 2014].

\section{Study theory.}

Actually, in physics and education, contemporary tendencies suggest reconstruction of knowledge, and therefore, traditional or new technologies should be addressed to such an aim [13. Alizoti et al., 2013]. As visual display is an important component of physics and its education, working with images has always turned to be an essential part of computer requirements. For this reason, computer technologies have been forced to develop an extra color model need for basical replacement of no more. The color model is device-dependent and based on RGB colors, known as Red colors (0-255), Green colors (0-255) and Blue colors (0-255). The RGB color model is available to many Windows based object oriented authoring languages, i.e. Delphi [21. Fisher et al., 2019]. 
Values of RGB colors are displayed in tables below, also indicating the way they should be applied, table 1 , table 2 , table 3 .

\section{Table 1}

\begin{tabular}{|c|c|c|c|}
\hline Red Colors $\backslash$ RGB & Red & Green & Blue \\
\hline Reds & 255 & 0 & 0 \\
\hline Reds & 254 & 0 & 0 \\
\hline Reds & $\ldots$ & 0 & 0 \\
\hline Reds & 2 & 0 & 0 \\
\hline Reds & 1 & 0 & 0 \\
\hline
\end{tabular}

Table 2

\begin{tabular}{|c|c|c|c|}
\hline Green Colors $\backslash$ RGB & Red & Green & Blue \\
\hline Greens & 0 & 255 & 0 \\
\hline Greens & 0 & 254 & 0 \\
\hline Greens & 0 & $\ldots$ & 0 \\
\hline Greens & 0 & 2 & 0 \\
\hline Greens & 0 & 1 & 0 \\
\hline & 0 & 0 & 0 \\
\hline
\end{tabular}

\section{Table 3}

\begin{tabular}{|c|c|c|c|}
\hline Blue Colors $\backslash$ RGB & Red & Green & Blue \\
\hline Blues & 0 & 0 & 255 \\
\hline Blues & 0 & 0 & 254 \\
\hline Blues & 0 & 0 & $\ldots$ \\
\hline Blues & 0 & 0 & 2 \\
\hline Blues & 0 & 0 & 1 \\
\hline & 0 & 0 & 0 \\
\hline
\end{tabular}




\section{Method.}

Delphi is a powerful object oriented authoring programming language and offers great possibilies to work with images [22. White, Alizoti, 2000]. Using Delphi's components and functions, simple applications and procedures can be developed to analyse images.

There is an example of the blue colors analyses:

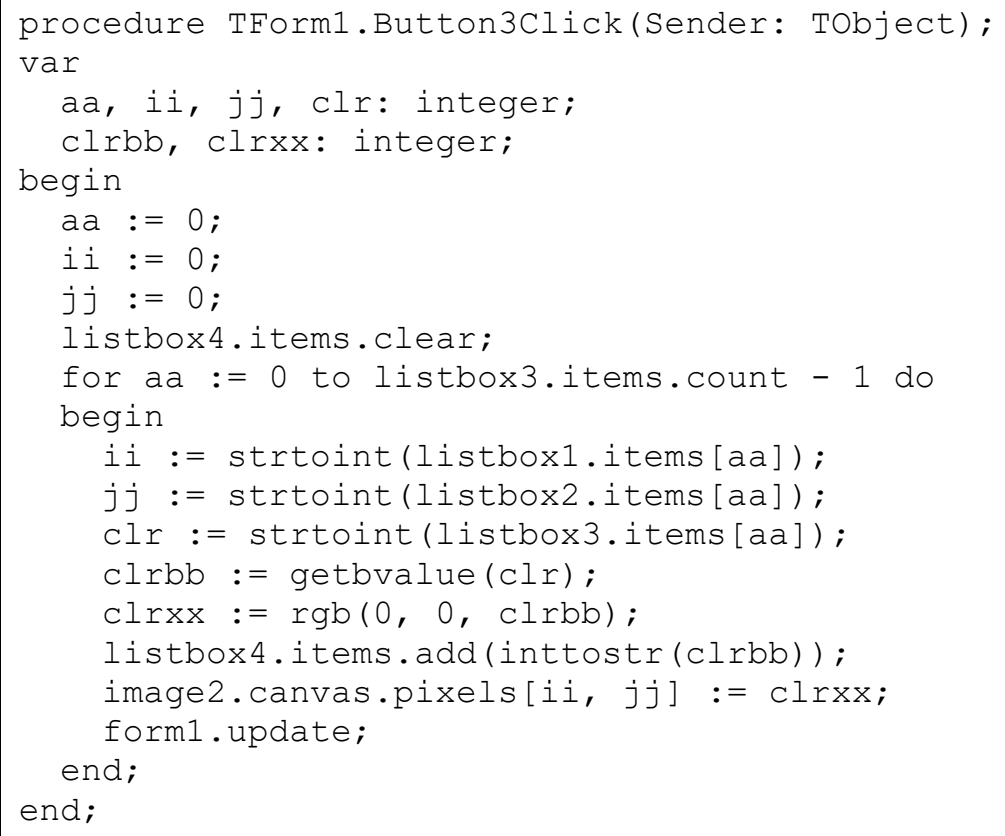

Four images are selected from public internet, and processed with Delphi's RGB functions by each pixel.

1. Universal world - Image from our Universe [23. The Whirlpool Galaxy Real Space]

2. Macro world - Image from Earth site [24. Worldatlas]

3. Human activities - Painting [25. Monet, Regatta At Argenteuil]

4. Micro world - Image of a single Atom [26. Quantum microscope]

Processing results are displayed below: 


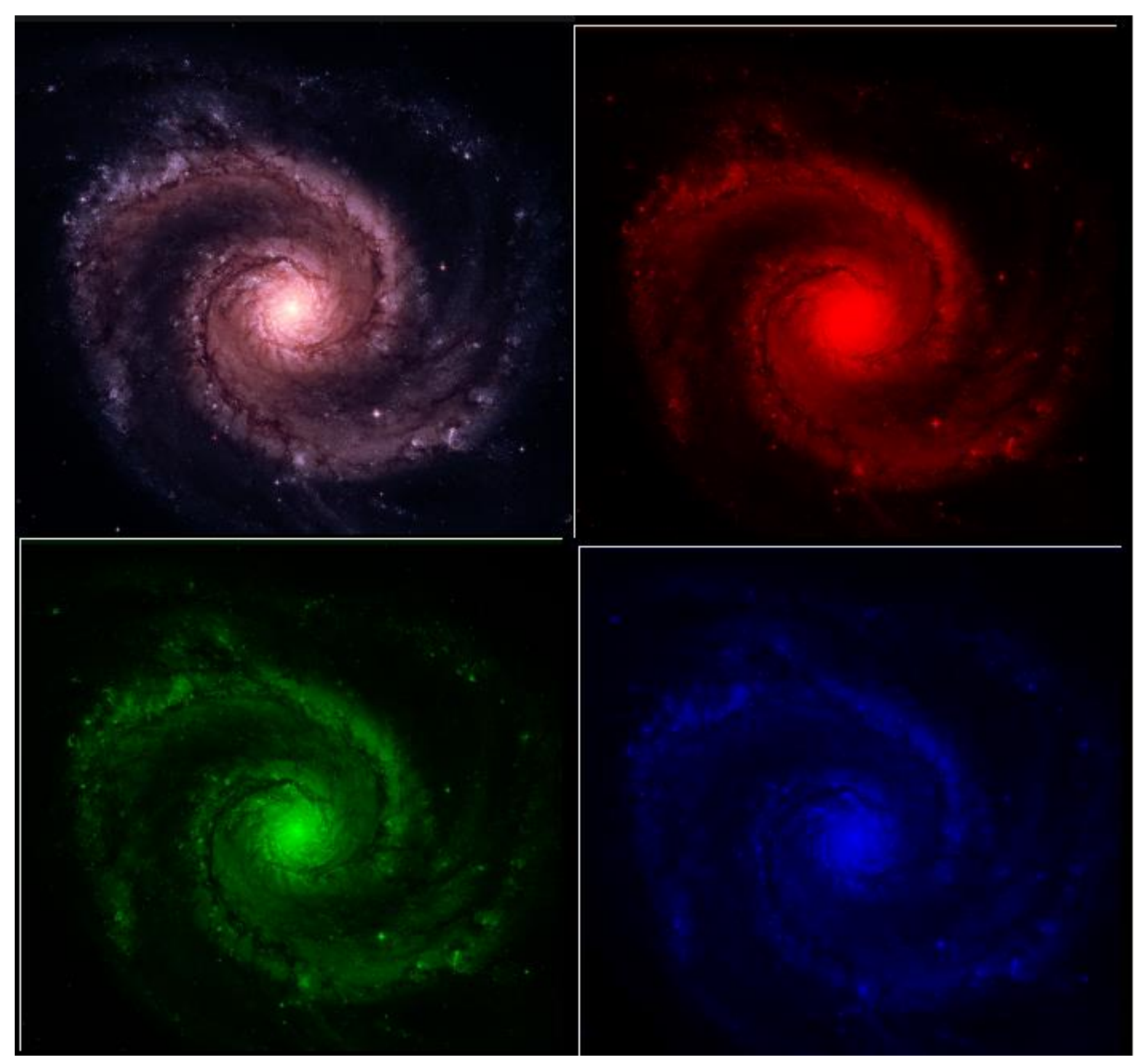

Reader's top - left image: Original image

Reader's top - right image: Red colors distribution 
Reader's bottom - left image: Green colors distribution

Reader's bottom - right image: Blue colors distribution

Notice that images have similar designs, but different colors. 

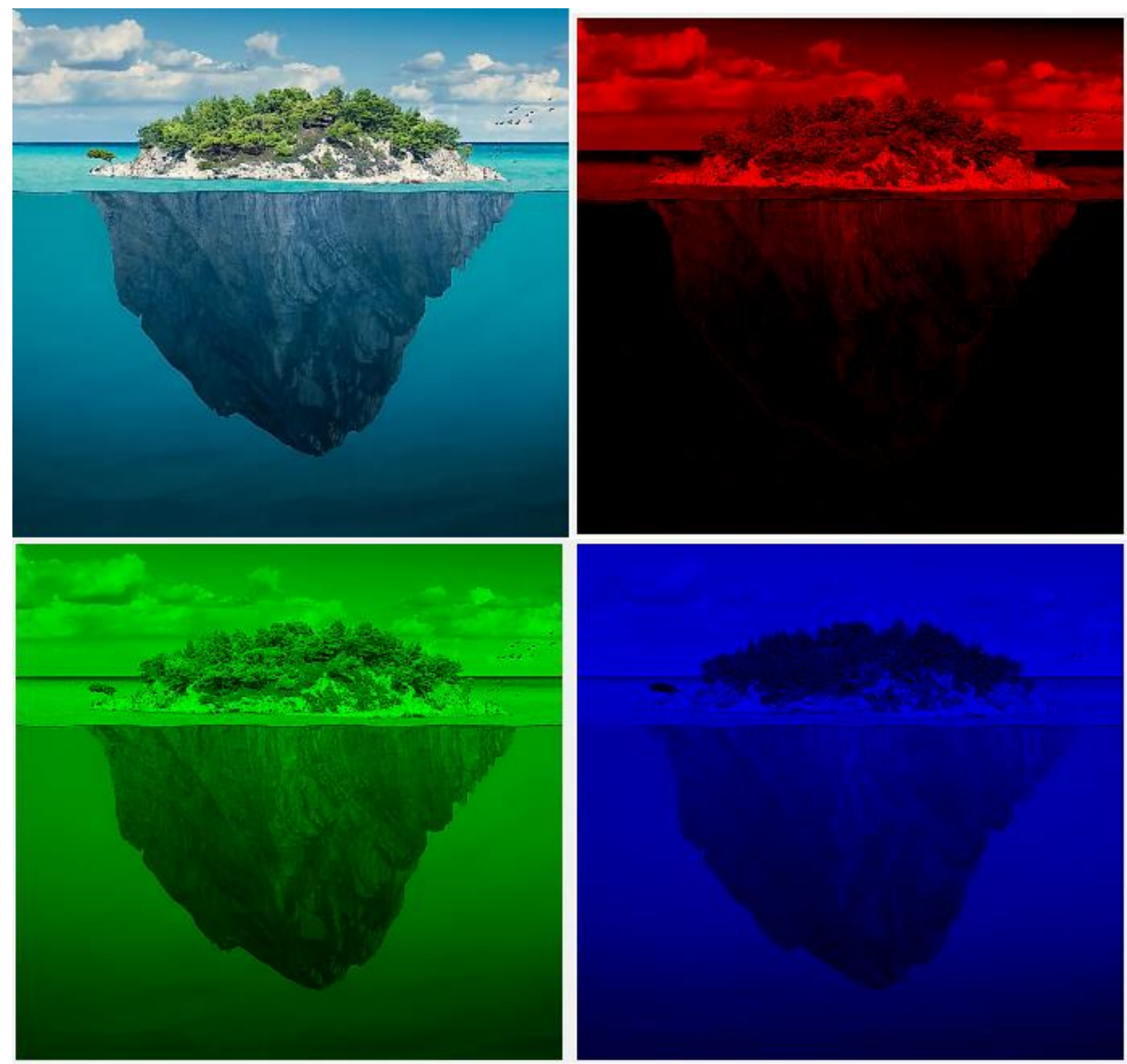

Reader's top - left image: Original image

Reader's top - right image: Red colors distribution

Reader's bottom - left image: Green colors distribution

Reader's bottom - right image: Blue colors distribution

Notice that images have similar designs, but different colors. 

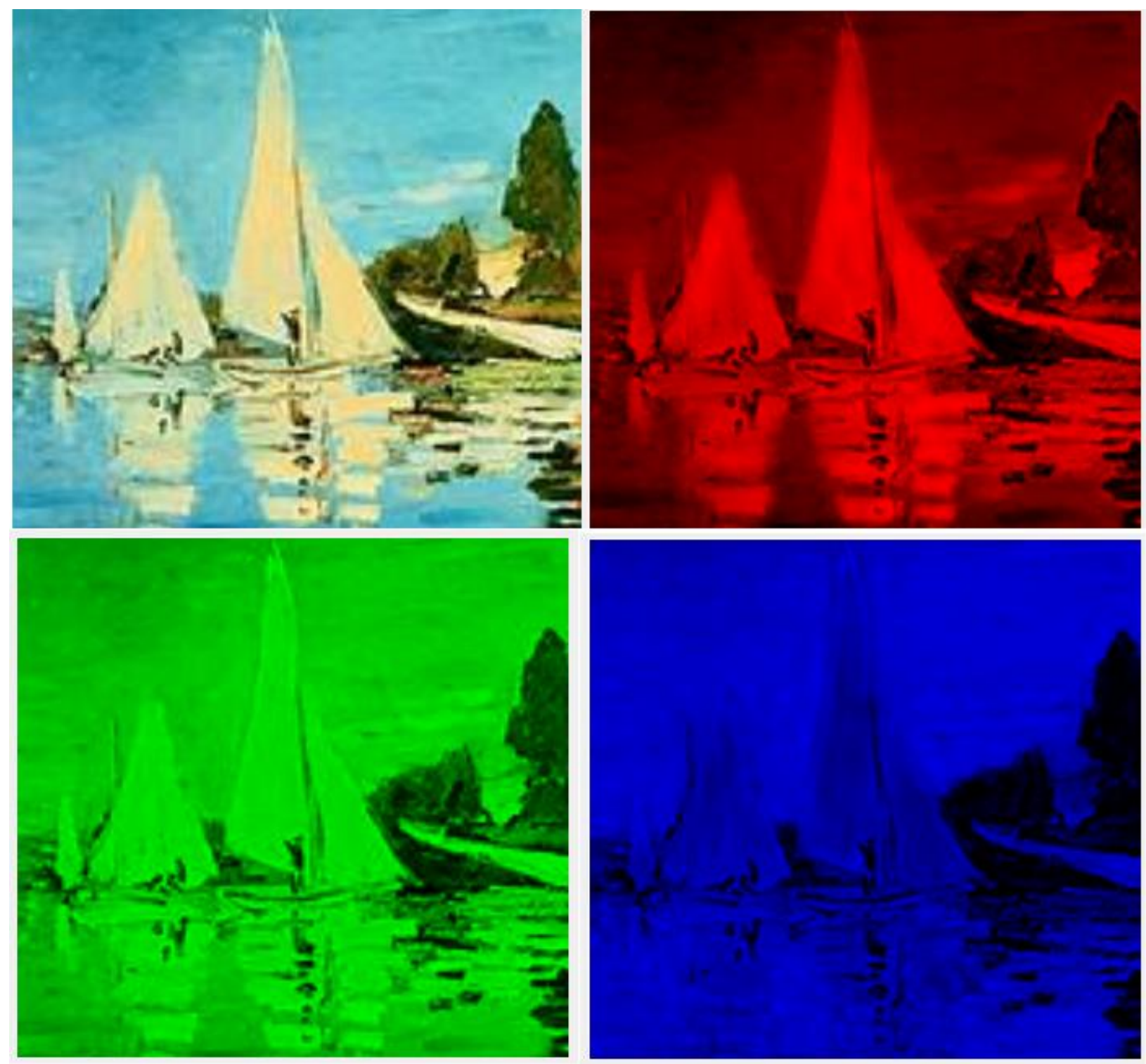

Reader's top - left image: Original image

Reader's top - right image: Red colors distribution

Reader's bottom - left image: Green colors distribution

Reader's bottom - right image: Blue colors distribution

Notice that images have similar designs, but different colors. 


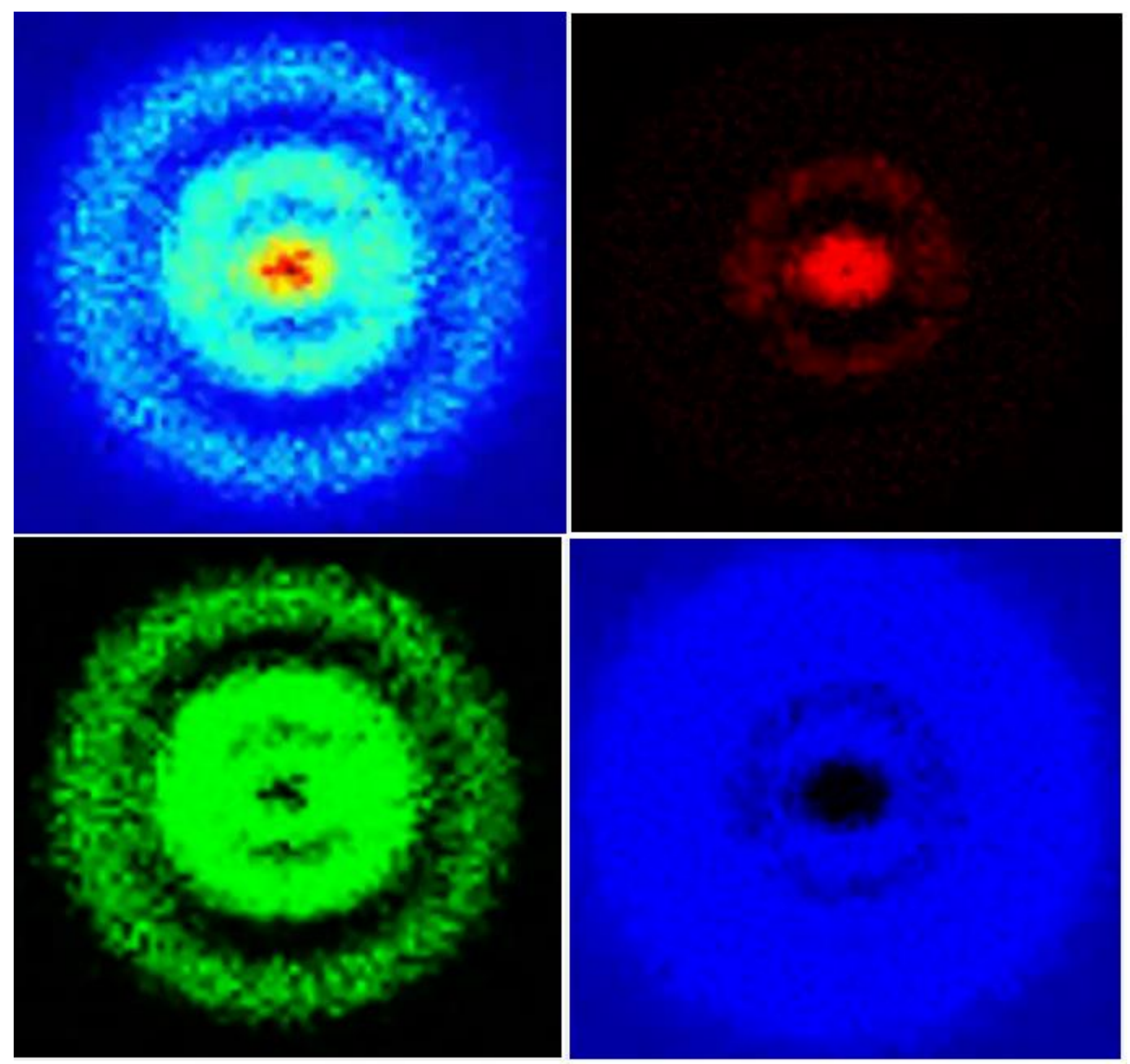

Reader's top - left image: Original image

Reader's top - right image: Red colors distribution

Reader's bottom - left image: Green colors distribution

Reader's bottom - right image: Blue colors distribution

Notice that images have neither similar designs, nor colors. 


\section{(1) TECHNIUM}

Technium Vol. 3, Issue 8 pp.1-12 (2021)

ISSN: $2668-778 X$

www.techniumscience.com

\section{Conclusions.}

RGB color analysis is a fascinating computer proccess giving new insights to natural images. However, experiences have shown that students prefer original images instead. Thus, it is crucial to explain to them, that image analysing is extremely important to detailed scientific research. For instance, a single central vertical line of the original image from micro world (figure 4), produces a set of about 300 pixels and 900 color values data ( 300 pixels; 300 of reds; 300 of greens; 300 of blues). Using these data with an Excel table sheet, three distributions graphs can be built of, figure 5.
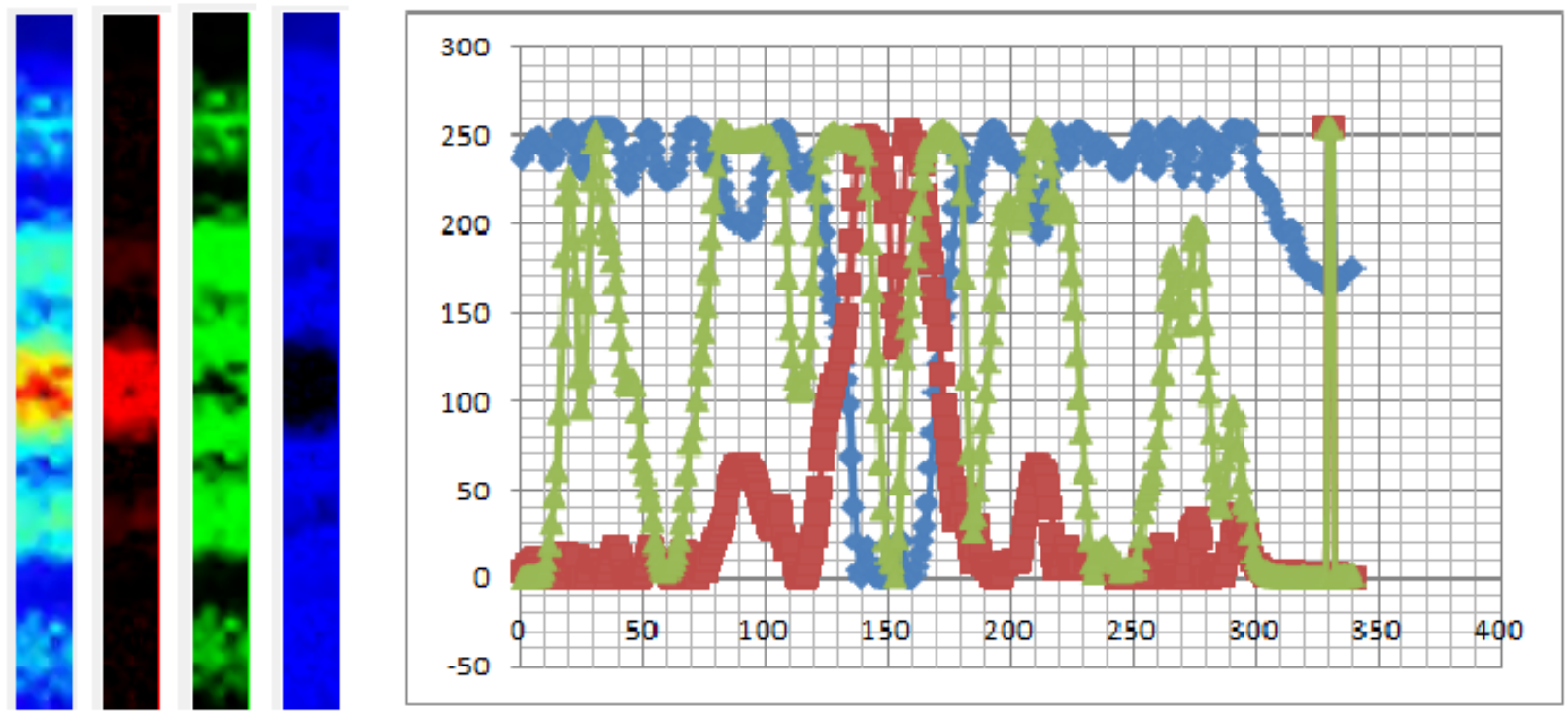

It is clearly shown that near center, red color distribution goes high peek, while blue color goes down. Along to them, green color distribution shows off some non - linear oscillations, well known to science and engineerings [27. Rahmani et al., 2020].

From the RGB perspective, all these four images, original and analysed, demonstrate that nature, as assumed to be, is all of the same, from the top of the universe to the bottom of the micro world, al least so far.

\section{References}

[1]. Stanford Encyclopedia of Philosophy (2000) The Modern History of Computing, https://plato.stanford.edu/entries/computing-history

[2]. https://history-computer.com, History of Computers and Computing, Birth of the modern computer, The bases of digital computers, typewriter and computer keyboard, historycomputer.com, Archived from the original on 2016-09-05, Retrieved 2016-09-19. 
[3]. CG101: A Computer Graphics Industry Reference, ISBN 073570046X, Unique and personal histories of early computer graphics production, plus a comprehensive foundation of the industry for all reading levels.

[4]. M. M. Carević, M. Ilić, M. Petrović, N. Denić (2020) Computing support for testing equal values of the figurative numbers in the Pascal triangle, Technium Vol. 2, Issue 7 pp.36-41 (2020) ISSN: 2668-778X www.techniumscience.com

[5]. M. M. Carević, M. J. Petrović, N. Denić, A. Mitrović, 2020 Computing Support in Statistical Evaluation of Mathematics Teaching Effectiveness: Development of Students' Constructive Thinking, Technium Vol. 2, Issue 4 pp.109-115 (2020) ISSN: 2668-778X www.techniumscience.com

[6]. J. D. Foley, A. van Dam, S. K, Feiner, J. Hughes (1990) Computer Graphics: Principles and Practice (2nd ed.), Addison-Wesley, ISBN 978-0-201-12110-0

[7]. J. Beck (2005) The Animated Movie Guide, Chicago Review Press, ISBN 1569762228.

[8]. C. White, A. Alizoti, (1995) Computer - Aided Visualisation of Similarities in Physics, Open University ALT - C 95 Milton Keynes, Association for Learning Technology, Milton Keynes, UK

[9]. A. Alizoti, C. White (1997) Simulating with computer the physical phenomena, Babeş Bolyai University, Cluj Napoka BPU - 3 Rumani, Third General Conference of the Balcan Physical Union, Balcan Physics Letters, Romania.

[10]. A. Alizoti, R. Çorati (1995), Simulating with the computer - A Pedagogical Approach, National Conference of Physics, Antalya, Turkey.

[11]. C. Fratila, T. Axinte, R. C. Cojocaru, C. Berescu, I. C. Scurtu (2020) The study of the lifting mechanism of the crane arm to a barge, Technium Vol. 2, pp. 91-96, (2020) ISSN: 2668778X www.techniumscience.com

[12]. https://phet.colorado.edu/en/simulations/filter?subjects=physics\&type=html\&sort=alpha\&vi ew $=$ grid

[13]. A. Alizoti, F. Vila, Z. Mulaj, P. DHoqina (2013) Contemporary Tendencies in Physics Education, (poster) $2^{\text {nd }}$ International Conference, Research and Education in Natural Sciences, November, 2013 15-16, Shkoder - Albania, Procedings, Vol. 1, pp. 637-642, 2013 ISBN987-9928-4135-5-0

[14]. A. Alizoti, F. Vila, Z. Mulaj, P. DHoqina (2020) Compiuter technologies assist potential energy with experiments, TECHNIUM, Romanian Journal of Applied Sciences and Technology Technium Vol. 2, Issue 7 pp.297-302 (2020) ISSN: 2668-778X www.techniumscience.com

[15]. A. Alizoti (2021) Computer on - line to study the energy issue among collisions, TECHNIUM, Romanian Journal of Applied Sciences and Technology Technium Vol. 3, Issue 4 pp.57-62 (2021) ISSN: 2668-778X www.techniumscience.com

[16]. A. Alizoti, Z. Mulaj, F. Vila, P. Dhoqina (2015) New technologies for time temperature measurements in medicine, (poster) herstpo2015, University Luigj Gurakuqi Of Shkodra, Albania, 2015, Proceedings Book, Vol 1, pp 205 - 209, ISBN:987-9928-4135-9-8

[17]. A. Alizoti, P. Dhoqina (2021) STUDIMI EKSPERIMENTAL I TERMOMETRIT TË GALILEUT, Buletini Shkencor, Fakulteti i Shkencave të Natyrës, Buletini i Shkencave të Natyrës, ISSN 2305-882X

[18]. https://www.vernier.com/product/logger-pro-3/ 
[19]. https://internetworldstats.com, World Internet Users Statistics and 2019 World Population Stats

[20]. S. Bebbington (2014) What is programming, Tumblr. https://yearofcodes.tumblr.com/whatis-programming

[21]. R. Fisher, S. Perkins, A. Walker, E. Wolfart, Hypermedia Image Processing Reference, University of Edinburgh, https://www.researchgate.net/publication/246405203_Hypermedia_Image_Processing_Refer ence_HIPR/link/553a1bb20cf29b5ee4b43b00/download

[22]. C. White, A. Alizoti, (2000) DELPHICAL - Delphi Computer Aided Learning, University of Sofia, Veliko Turnovo BPU - 4 Bullgari, Fourth General Conference of the Balcan Physical Union, Balcan Physics Letters, Bullgari.

[23]. https://www.deviantart.com/omniomi/art/M51-The-Whirlpool-Galaxy-Real-Space$\underline{367099940}$

[24]. https://www.worldatlas.com/r/w1200-h630-c1200x630/upload/9c/99/76/shutterstock428582293.jpg

[25]. https://www.paintinghere.com/uploadpic/claude\%20monet/big/Regatta\%20At\%20Argenteui 1.jpg

[26]. https://wordlesstech.com/quantum-microscope-sees-the-hydrogen-atom-for-the-first-time/

[27]. M. Rahmani, I. C. SCURTU, A. Moslemi Petrudi (2020) Analytical and Dynamic study of Pulled Mass Nonlinear Vibration by Two Cables using Newton's Harmonic Balance Method, Technium Vol. 2, Issue 2, pp. 79-86, (2020) ISSN: 2668-778X www.techniumscience.com 